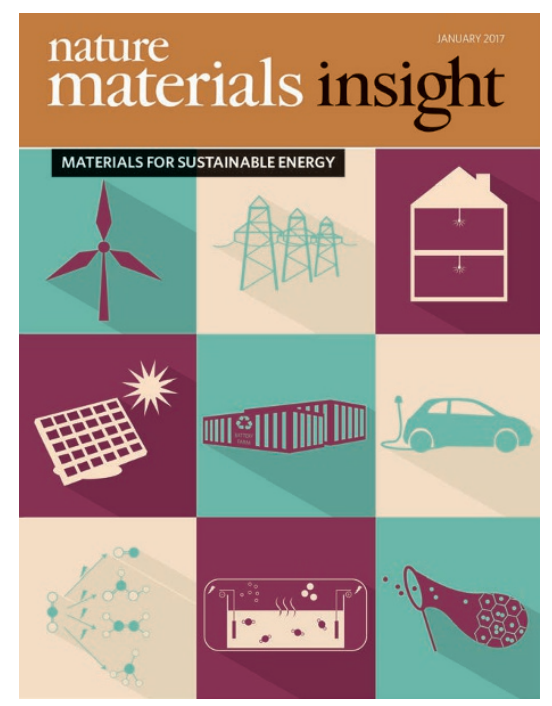

COVER IMAGE

Advances in materials science are leading to more efficient technologies for electricity generation from renewable sources, energy use and storage, and the capture and conversion of carbon dioxide.

IMAGE: PALOMA LIU

\section{SPRINGER NATURE LONDON \\ The Campus, 4 Crinan Street, \\ London N19XW \\ $\mathrm{T}:+442078334000$ \\ F: +442078434563 \\ materials@nature.com}

CHIEFEDITOR

VINCENT DUSASTRE

INSIGHT EDITORS

VINCENT DUSASTRE

LUIGI MARTIRADONNA

SENIOR COPY EDITOR

KEVIN SHERIDAN

COPY EDITOR

TIM BODICOAT

SENIOR PRODUCTION EDITOR

ALISON HOPKINS

ART EDITOR

TULSI VORALIA

EDITORIAL ASSISTANT

STEPHEN DUNNELL

MARKETING MANAGER

REBECCA BUCKLEY

EXECUTIVE EDITOR

ALISON WRIGHT

EDITOR-IN-CHIEF,

NATURE PUBLICATIONS

PHILIP CAMPBELL

SPRINGER NATURE

\title{
Materials for sustainable energy
}

$\Lambda$ vailable and affordable energy has so far led to spectacular industrialization and development, but with growth accelerating in developing countries, demands on non-renewable energy sources are reaching their limits. Moreover, the recent confirmation that global warming is due to the increase of greenhouse gases in the atmosphere, together with the uneven global distribution of energy sources, urgently requires drastic changes in the way we generate and supply energy.

To deal with these rapid changes we need to simultaneously develop innovative strategies to regulate the price of carbon emissions, reduce the costs of generating energy from renewable sources, and develop greener, cheaper and scalable technologies for energy production and storage. Overall, these technologies must rely on earthabundant and recyclable materials selected according to their entire life-cycle impact, as well as on clean and affordable processes, to ensure long-term sustainability. This principle should also be applied to other technologies such as nuclear power, carbon capture and storage, and biofuels.

The aim of this Insight is therefore to focus on what materials-based solutions can offer and to show how the rational design and improvement of materials properties can lead to energy alternatives that can compete with existing technologies. In terms of alternative means of electricity generation, dramatic fundamental and practical breakthroughs are taking place in the realization of solar cells with high energy-conversion efficiency. The improvement of batteries for electric vehicles and the grid is also a major challenge. Key advances in sustainable approaches beyond $\mathrm{Li}$-ion batteries and progress towards operando techniques for in situ monitoring and control of redox processes are greatly needed. The conversion of sunlight into fuels and chemicals is also an attractive prospect for energy storage, and major efforts to develop efficient catalysts for both water splitting and $\mathrm{CO}_{2}$ reduction are under way.

Many difficulties remain, and researchers are working hard to overcome outstanding hurdles by designing improved materials and devices. Yet, this is not a road scientists should walk alone - the impact that wiser energy management can have on global warming and human health is huge, and requires ongoing attention from policy-makers. The recent Paris climate agreement demonstrates that strategies to ensure both economic growth and climate protection can be successful if coordinated internationally. However, such long-term support must be sustained globally, as the challenge is not just to preserve our environment, but how to save our planet.

Vincent Dusastre, Chief Editor Luigi Martiradonna, Senior Editor

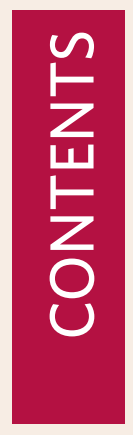

\section{PERSPECTIVE}

The path towards sustainable energy

Steven Chu, Yi Cui and Nian Liu

\section{REVIEW ARTICLES} Energy conversion approaches and materials for
high-efficiency photovoltaics

Martin A. Green and Stephen P. Bremner

Photovoltaic concepts inspired by coherence effects in photosynthetic systems

Jean-Luc Brédas, Edward H. Sargent and Gregory D. Scholes

Sustainability and in situ monitoring in battery development

C. P. Grey and J. M. Tarascon

Energy and fuels from electrochemical interfaces

Vojislav R. Stamenkovic, Dusan Strmcnik, Pietro P. Lopes and Nenad M. Markovic

Materials for solar fuels and chemicals Joseph H. Montoya, Linsey C. Seitz, Pongkarn Chakthranont, Aleksandra Vojvodic, Thomas F. Jaramillo and Jens K. Nørskov 